\title{
Anthropogenic impacts on the contextual morphological diversification and adaptation of Nile tilapia (Oreochromis niloticus, L. 1758) in East Africa
}

\author{
Papius Dias Tibihika • Herwig Waidbacher • Charles Masembe • Manuel Curto • \\ Stephen Sabatino • Esayas Alemayehu • Paul Meulenbroek • Peter Akoll • \\ Harald Meimberg
}

Received: 28 May 2017 / Accepted: 4 December 2017 / Published online: 8 January 2018

(C) The Author(s) 2018. This article is an open access publication

\begin{abstract}
Nile tilapia occurs naturally in East Africa where it's an economically important species. Many of the natural populations of Nile tilapia have been affected by anthropogenic activities including translocations, associated with programmes aimed at enhancing capture fisheries and aquaculture productivity. Using geometric morphometric analyses, we tested the hypothesis that such anthropogenic activities have augmented admixture among natural populations of Nile tilapia and
\end{abstract}

P. D. Tibihika • M. Curto · E. Alemayehu $\cdot$ H. Meimberg Institute for Integrative Nature Conservation Research, University of Natural Resources and Life Sciences (BOKU) Vienna, Gregor Mendel-Straße 33, 1180 Wien, Austria

\section{P. D. Tibihika $(\bowtie)$}

National Agricultural Research Organization, Kachwekano Zonal Agricultural Research and Development Institute, P.O. Box 421, Kabale, Uganda

e-mail: papius.tibihika@students.boku.ac.at

e-mail:papiust@yahoo.com

H. Waidbacher · P. Meulenbroek

Institute of Hydrobiology and Aquatic Ecosystems Management, University of Natural Resources and Life Sciences (BOKU)

Vienna, Gregor-Mendel-Straße 33/DG, 1180 Wien, Austria

C. Masembe $\cdot$ P. Akoll

Department of Zoology, Entomology and Fisheries Sciences, Makerere University Kampala, P.O. Box 7062, Kampala, Uganda

S. Sabatino

CIBIO, Research Center in Biodiversity and Genetic Resources / InBio Associated Laboratory, University of Porto, Rua Padre Armando Quintas 7, 4485-661 Vairão, Portugal influenced the geographical distribution of morphological variation within the species. Our expectation was that Nile tilapia shape divergent might be consistent with reportedly anthropogenic activities in nonnative environments. To test this hypothesis, we analyzed the shapes of 490 individuals from thirteen populations; three farms, six natives and four nonnative natural populations. Our analysis revealed that the most pronounced shape diversification was observed in seven populations; three nonnatives (Victoria, Kyoga and Sindi farm) and four natives (Albert, River Nile, George and Turkana). The features responsible for the observed morphotypes were mainly related to the orientation of the anterior region of the fish and may be due to diversifying selection in response to new environmental pressures (for nonnative populations), admixture or drift. Shape change in the nonnative high-altitude populations was unexpectedly conserved, suggesting recent introductions which may have not resulted in admixture or there was strong selection against change in the traits measured. On the other hand, the recorded morphotypic clusters explained the possible genetic link to their putative ancestral home. Our results were partially consistent with our prediction that the nonnative populations exhibited divergent morphotypes. We recommend further investigations with molecular genetics for followup of these findings.

Keywords Nile tilapia - Geometric morphometrics . MorphoJ · Populations · Condition factor . Morphological diversification 


\section{Introduction}

Nile tilapia (Cichlid) is one of the many native East African (EA) freshwater species that have been greatly impacted by anthropogenic activities. Partly due to the ease in which tilapia can be farmed and thrive when introduced into new areas and its market demand, the species has now been spread well beyond its native ranges via human-mediated translocations associated with aquaculture (George 1995; Vreven et al. 1998; Eknath et al. 2007). The species is also stocked in many natural environments but overfishing has decimated native populations. The impact of these potential stressors on native Nile tilapia however, have not been well studied.

In EA, Nile tilapia is native to the Lakes George, Edward, Albert, Kivu, Tanganyika, Turkana, Baringo and to the River Nile (Trewavas 1983; Ogutu-Ohwayo 1990; Agnèse et al. 1997). The cichlid was introduced to the remaining large water bodies, lakes Victoria, Kyoga, Nabugabo and to numerous satellite lakes including various aquaculture setups (Ogutu-Ohwayo 1990; Boyd 2004). Generally, the main motive of Nile tilapia translocations in EA was to reinforce the fishery after native species had been overfished, and to stock water bodies that had been considered naturally unproductive (Balirwa 1994, 1992). Apparently, Nile tilapia in nonnative water bodies since the $1950 \mathrm{~s}$, has become the commercially most important Tilapiine (Ogutu-Ohwayo 1990) in particular after many native fish species had declined due to competition as has been well studied in Lake Vitoria (Witte et al. 2007).

The success of stocking Nile tilapia in nonnative environments is attributed to several factors including its opportunistic omnivore, growth rate, and prolific breeding in artificial and natural ecosystems, the species strategies of predator avoidance and diversified habitats (Ogutu-Ohwayo 1990; Balirwa 1992; Eknath et al. 2007). The effectiveness of Nile tilapia to thrive in a broad range of habitats may also be reflected in the condition coefficient or factor of the species. Condition factor $(\mathrm{K})$ of fish, also referred to as Fulton's condition factor, predicts the adaptability of the species by determining the status of the individual as weight at a given length (Ricker 1975). Adaptability might be one expression of a population's ability for morphological diversification that can be induced environmentally, either as a plastic or evolutionary response (Moczek et al. 2011). In extreme cases, morphology can diverge into distinct types as evolutionary response to resource polymorphism (Robinson and Wilson 1994; Eklöv and Svanbäck 2005). Morphology can be influenced by a variety of environmental forces. This might not only occur in response to environmental pressures, but also adaptation to mimic against predation, defend territories and for foraging functions (Mekkawy and Mohammad 2011; ElZaeem et al. 2012). For example, Crucian carp, Carassius carassius, developed deeper body morphotypes to somewhat render predator's difficulty for handling (Scharnweber et al. 2013). Pumpkinseed sunfish (Lepomis gibbosus) have also diversified their shapes with increased body depths and dorsal fins in response to predator threats, (Januszkiewicz and Robinson 2007).

Nevertheless, divergence of phenotypic traits might be induced anthropogenically. When, for instance organisms are shifted from their natural habitats, as has been the case for Nile tilapia in EA, possible admixture may lead to shape changes when divergent gene pools are brought together and form recombinant individuals, as in form of hybridization (Sinama et al. 2013). Hybrids might form typical morphs divergent from their parent lines. For example, hybrid specimen from cyprinid fish species have been reported to show extreme body forms resulting from widening of the lower lip of their mouths contrary to their parental lines (Corse et al. 2012), as an example for transgressive segregation (Seehausen 2004; Sinama et al. 2013).

In Nile tilapia, hybridization with its congeneric species has been reported in Lake Edku, Egypt and in River Kafue, Zambia by Bakhoum et al. (2009); Deines et al. (2014) respectively. It is possible that in EA, Nile tilapia admixture might be complex, likely an intermingle of species from various sources including aquaculture, either intentional or accidental escapees. Despite the possibility of admixture leading to various species' morphs, the result might also pose other constraints to the populations. For example, Perrier et al. (2013) indicated loss of local adaptation and fitness reduction in wild Salmonids resulting from captive salmonids admixture. In cases where admixture leads to fitness reduction, natural reinforcements might result into displacement of the less fit characters to the periphery and hence the evolution of distinct morphotypes (Dodson et al. 2015). On the other hand, generated fit hybrids might form new populations that remain distinct from the ancestry lines, a condition which may lead to hybrid speciation (Mallet 2007). Therefore, critical studies linking anthropogenic influx on to species functionality 
across environmental gradients might provide a central goal in understanding evolutionary biology of organisms. This might be essential for management and conservation of the resource.

In EA, Trewavas (1983) and Vreven et al. (1998), delineated Nile tilapia morphotypes employing traditional morphometrics (TM). This involves physical linear measurements of the fish anatomical parts like head length, body depth, total length, standard length, eye diameter, fin lengths, mouth gape length, among others. TM approaches are time consuming, biased/subjective and have been criticized as uninformative (Maderbacher et al. 2008; Wilson et al. 2008; Ponton et al. 2013; Petrtyl et al. 2014). Besides, most studies focused on West African water bodies and Egypt, with little attention to EA. Some approaches on fish morphometry like geometric morphometrics (GM) have appeared to yield good results (Breno et al. 2011). GM is defined as the study of form in two or three dimensional spaces which induce in-depth investigation of morphological modelling in organisms (Bookstein 1982). GM allows the visualization and quantification of morphological differences in individuals represented by deformations of landmarks (Lms) in a coordinate space (Costa et al. 2010; Park et al. 2013). The arrangement of morphological Lms as data source and shape variation is extracted by Procrustes superimposition (Klingenberg 2011). When Maderbacher et al. (2008); Park et al. (2013); Ponton et al. (2013); Petrtyl et al. (2014), studied shape variations in fish comparing TM and Geometric morphometrics (GM), TM methodologies were realized weak contrary to GM. In addition, Rohlf (2002) employed GM while studying shape variation in Bluefin tuna, and was successful. Furthermore, comparisons between TM and GM on Mastomys natalensis (Rodentia: Muridae) skull morphology during growth, revealed GM more effective than TM (Breno et al. 2011). Use of GM thus proves that its application might be powerful and hence a likelihood of unleashing essential tools for cataloguing Nile tilapia populations in EA.

So far GM on Nile tilapia in EA is only available but limited to a few lakes and swamps in Kenya but with a larger scale missing (Ndiwa et al. 2016). It should, moreover, be a good method to link morphotypes in native and nonnative ranges with potential admixture given the numerous translocations. Nile tilapia populations react also to environmental factors, abiotic (low temperatures as for high altitudes) and biotic interactions, e.g. Nile perch predator influence. Comprehensive knowledge of the patterns of shape variation across various ranges by GM might be informative to determine such factors. The two principal advantages of the GM methodology include; 1) Geometric or shape information is extracted by means of Procrustes superimposition which filters variationally effects due to specimen size, position and orientation from the data (Klingenberg 2011). This procedure remains powerful, reliable and the most prevalent methodology that removes unnecessary variations in the data which would ultimately offer misleading information (Kerschbaumer and Sturmbauer 2011). 2) the mathematical portrayal of different morphs can be rendered as graphical images illustrating where the shapes differ, in which direction and by how much (Zelditch et al. 2012).

Using GM, the objective of this study was to investigate the impact of anthropogenic activities on morphological divergence and potential adaptation of Nile tilapia populations from various environments. Given the strong evidence of the species translocations to various nonnative zones in EA, we hypothesize that possible interspecific species admixture and varying environments might have led to morph divergence among the populations in the region. We determined morphological differences using GM for native and nonnative populations, including fish from aquaculture and nonnative highland in respect to $\mathrm{K}$. Investigating Nile tilapia K especially in nonnative high-altitude might be critical as the species lay at the edge of its physiological range (Popma and Masser 1999). With this approach, we answer the following questions; 1) Is condition factor (K) appropriate to explain adaptability or performance of Nile tilapia populations? 2) To what extent are the introduced populations morphologically different to their putative native sources? 3) At what level are the Lake Victoria metapopulations morphologically distant owing to potential multiple introductions or to its size?

\section{Materials and methods}

\section{Study areas/locations}

Nile tilapia species were sampled from water body types: (1) Fish farms (Sindi, Bagena \& Rwitabingi), (2) Lakes and Rivers with native populations (Albert, Edward, George, Turkana, Kazinga Channel \& River Nile), (3) low altitude lakes with introduced populations (Kyoga \& Victoria), and (4) high altitude Lakes with 
introduced populations (Mulehe and Kayumbu; Fig. 1). All the native populations are at a low altitude despite variations (Table 1).

Brief overview of sampling locations/studied sites

The number of sampling locations/sites per Lake or River depended on the size of the water body, and were set after consulting experienced fishermen and local government fisheries enforcement officers about the type of variation that exists in each habitat. In Lake Victoria, largest lake in Africa in terms of surface area, five locations were sampled in contrast to two and or one for Lakes Albert, Edward, Kyoga and George, Turkana, Mulehe, Kayumbu, respectively (Fig. 1; Table 1). The strong proportion of Uganda sampling sites resulted from the fact that five of the great East African Lakes and River; Victoria, Albert, Kyoga, Edward, George and River Nile, respectively lie within the country (Byrnes
2010). However, it should be noted that most of these herein mentioned water bodies in the region are shared, apart from L. Turkana (Kenya), Kyoga and George (Uganda). Lakes Edward and Albert are shared between Uganda and Democratic Republic of Congo (Former Zaire) and L. Victoria is shared amongst the three East African countries (Uganda, Kenya and Tanzania).

Many of the lakes are connected by channels or rivers, e.g. L. Victoria and lakes Kyoga and Albert link via River Nile; L. George is associated to L. Edward via a large flowing water mass, Kazinga Channel and L. Edward to L. Albert through River Semliki (Green 2009; Byrnes 2010; Cockerton et al. 2013), (also see Fig. 1). From the South-Western Ugandan High Altitude Lakes (satellites), Mulehe and Kayumbu (Table 1; Fig. 1), Kayumbu seems not to have any outlet but L. Mulehe connects to another satellite, L. Mutanda in the south via Mucha (a small river) which links via River Kaku to L. Edward (Green 2009; Tibihika et al. 2016). Nile tilapia

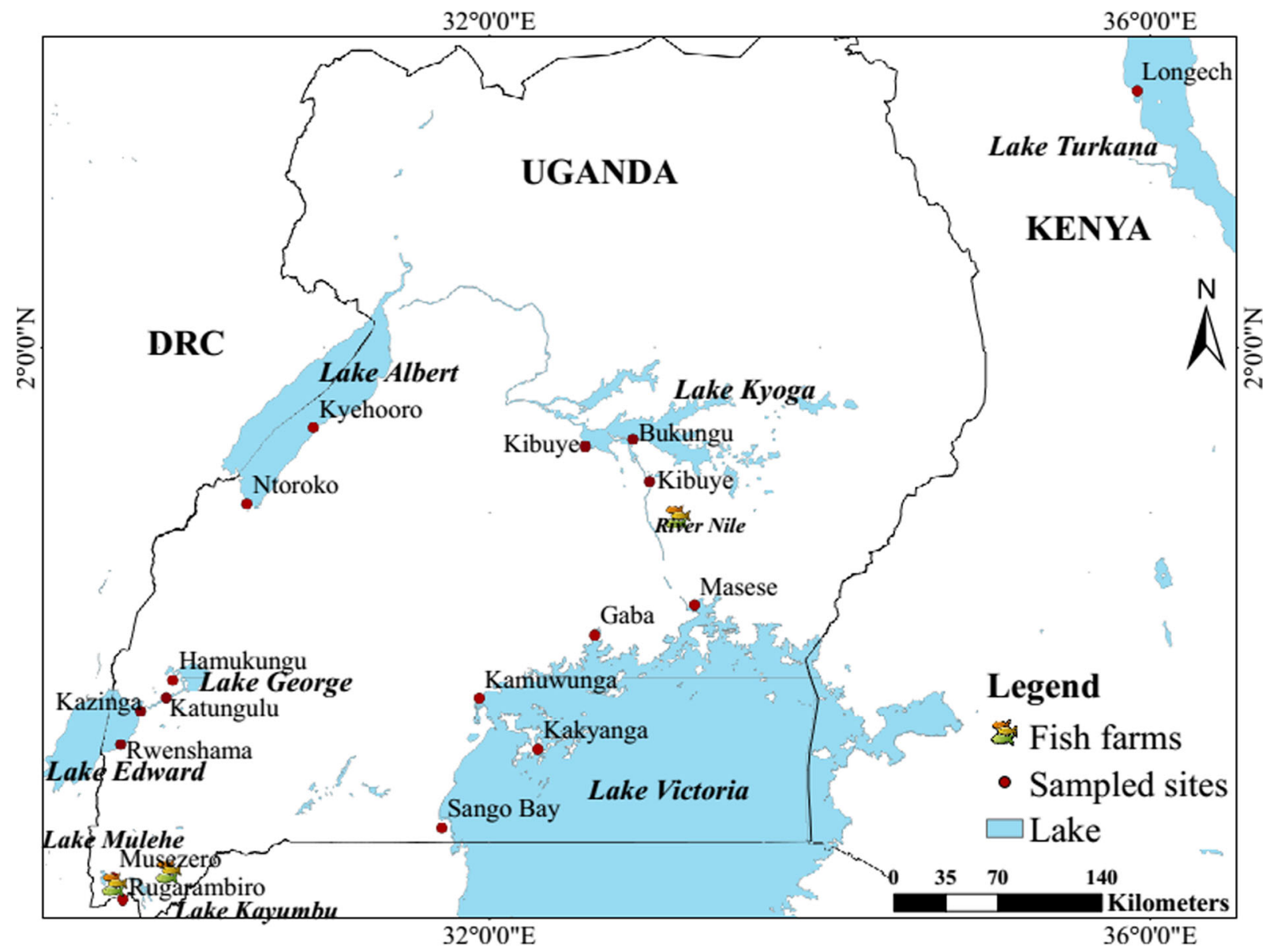

Fig. 1 Locations of sampling points for both natural and artificial populations. Artificial populations herein also are referred to as fish farms, pond culture 
Table 1 Detailed studied water bodies, locations, elevation and existing GPS coordinates for sites. The water bodies herein are also referred to as Nile tilapia populations, used in the current study

\begin{tabular}{|c|c|c|c|c|c|c|c|c|}
\hline Water body & Sample location & Elevation (masl) & Population type & No. & Size $(\mathrm{cm})$ & $\mathrm{Wt}(\mathrm{g})$ & \multicolumn{2}{|c|}{ UTM coordinates } \\
\hline Victoria & Kakyanga & 1136 & NNL & 37 & $30.9 \pm 3$ & $645.8 \pm 252.2$ & N. $00.18079^{0}$ & $\mathrm{E} 032.29332^{0}$ \\
\hline Victoria & Masese & 1136 & NNL & 30 & $16.8 \pm 1.8$ & $115.8 \pm 42.7$ & N. $00.43650^{\circ}$ & $\mathrm{E} 033.24081^{0}$ \\
\hline Victoria & Gaba & 1146 & NNL & 30 & $15.6 \pm 2$ & $91.3 \pm 34.7$ & N.00.25819 & $\mathrm{E} 032.63727^{0}$ \\
\hline Victoria & SBay & 1129 & NNL & 30 & $21.3 \pm 3.2$ & $233.1 \pm 106.6$ & N. $00.86772^{0}$ & $\mathrm{E} 031.71332^{0}$ \\
\hline Victoria & Kamu & 1139 & NNL & 30 & $20.2 \pm 4.7$ & $226.2 \pm 192.1$ & S. $00.12747^{0}$ & E031.93999 ${ }^{0}$ \\
\hline Albert & Ntoroko & 618 & $\mathrm{~N}$ & 30 & $33.2 \pm 3.6$ & $784.4 \pm 266.5$ & N.01.05206 ${ }^{0}$ & $\mathrm{E} 030.53464^{0}$ \\
\hline Albert & Kyehooro & 615 & $\mathrm{~N}$ & 16 & $32.0 \pm 3.9$ & $755.7 \pm 256.8$ & N. $01.50990^{0}$ & $\mathrm{E} 030.93610^{\circ}$ \\
\hline George & Hamukungu & 916 & $\mathrm{~N}$ & 40 & $20.2 \pm 4.7$ & $226.2 \pm 192.1$ & S. $00.01739^{\circ}$ & $\mathrm{E} 030.08698^{0}$ \\
\hline KazingaC & Katu & 915 & $\mathrm{~N}$ & 30 & $25.0 \pm 1.4$ & $350.6 \pm 41$ & S. $00.12541^{0}$ & $\mathrm{E} 030.04744^{0}$ \\
\hline Edward & Kazinga & 914 & $\mathrm{~N}$ & 30 & $30.9 \pm 1.9$ & $668.9 \pm 135.2$ & S. $00.20783^{0}$ & $\mathrm{E} 029.89252^{0}$ \\
\hline Edward & Rwensh & 908 & $\mathrm{~N}$ & 31 & $25.4 \pm 1.1$ & $363.7 \pm 46.2$ & S. $00.40459^{0}$ & $\mathrm{E} 029.77283^{0}$ \\
\hline Kyoga & Kibuye & 1034 & NNL & 50 & $19.8 \pm 1.8$ & $187 \pm 56.6$ & N.01.40028 & $\mathrm{E} 032.57949^{0}$ \\
\hline Kyoga & Bukungu & 1045 & NNL & 30 & $24.6 \pm 2.7$ & $359.4 \pm 124$ & N.01.43873 ${ }^{0}$ & $\mathrm{E} 032.86809^{0}$ \\
\hline RiverN & Kibuye & 1062 & $\mathrm{~N}$ & 30 & $23.4 \pm 3.0$ & $300.2 \pm 110.8$ & N.01.18734 $4^{0}$ & $\mathrm{E} 032.96865^{\circ}$ \\
\hline Mulehe & Musezero & 1801 & $\mathrm{NNH}$ & 31 & $21.8 \pm 1.7$ & $235.7 \pm 59.7$ & S. $01.21345^{0}$ & E029.72668 ${ }^{0}$ \\
\hline Kayumbu & Ruga & 1901 & $\mathrm{NNH}$ & 34 & $17.2 \pm 2.1$ & $116.7 \pm 38.1$ & S. $01.34679^{0}$ & $\mathrm{E} 029.78446^{0}$ \\
\hline Bagena & Bfarm & 1857 & Farm & 35 & $16.7 \pm 4.2$ & $104.7 \pm 86$ & S.01.25617 & $\mathrm{E} 029.73622^{0}$ \\
\hline Sindi & Sindi farm & 1733 & Farm & 30 & $20.3 \pm 1.5$ & $165.3 \pm 28.3$ & S. $01.17578^{0}$ & $\mathrm{E} 030.06198^{0}$ \\
\hline Rwita & Rfarm & 1069 & Farm & 30 & $20.4 \pm 1.5$ & $156.7 \pm 31.5$ & N. $00.97116^{0}$ & E033.13924 ${ }^{0}$ \\
\hline Turkana & Longech & 364 & $\mathrm{~N}$ & 40 & $24.4 \pm 3.4$ & $308.9 \pm 118.6$ & N.03.55617 & $\mathrm{E} 035.91599^{0}$ \\
\hline
\end{tabular}

masl meters above the sea level, No Number of samples, UTM Universal Transverse Mercator coordinate system, KazingaC Kazinga Channel, RiverN River Nile, Rwita Rwitabingi. SBay Sango Bay, Kamu Kamuwunga, Katu Katungulu, Rwensh Rwenshama, Ruga Rugarambiro, Bfarm Bagena farm, Rfarm Rwitabingi farm, $N N L$ Nonnative low altitude, $N$ Native, $N N H$ Nonnative high altitude

stocking in Lakes Mulehe and Kayumbu is reported to have taken place between 1920s and 1950s (ISSION 1960; Green 2009), with some reports from the Local Government archives indicating restocking continued up to the 80 s. L. Turkana (previously called Rudolf), located in the Great Eastern Rift Valley is the largest freshwater body in Kenya (Kolding 1992). The Lake lies in the arid North-Western part of Kenya at an altitude of $364 \mathrm{~m}$ above the sea level, much lower than most of the other East African freshwater bodies (Table 1). Surprisingly, despite L. Turkana having much of its inlet from River Omo (originating from Ethiopian highlands), the Lake does not have any surface outlet and hence, the water balance is compensated for by evaporation, estimated at 2.3-2.8 m/yr. (Kolding 1992). Peripheries for most of these lakes are populous and user conflicts have amplified the demand for fisheries resources culminating into overfishing (Ogutu-Ohwayo et al. 1997). Previous limnological studies regarding the herein mentioned EA water bodies have indicated increased eutrophication, with oxygen levels and transparency (Secchi depths) decreasing, Chlorophyll $a$ and siltation increasing, among others, all attributed to environment/catchment destruction particularly in Lake Victoria basin (Njiru et al. 2012). Additionally, translocations of fish species to nonnative homes, for instance a voracious predator, Nile perch (Lates niloticus) from Lake Albert to Victoria, Kyoga and Nabugabo, also have left majority of the cichlids depleted through predation pressure, a concern to the future sustainability of the resources (OgutuOhwayo et al. 1997). Therefore, it was thoughtful for sampling the above various water bodies for unfolding insights into the current form of Nile tilapia.

Fish sampling procedures

Samples were mainly collected by gill nets overnight apart from one sampling location, L. Victoria (Gaba) where a cast net was employed and a beach seine net on L. Turkana. Upon landing, specimens were inspected by 
eye for possible morphological malformations. In cases where samples were malformed due to fishing artefacts, they were rejected and hence not utilized for subsequent analysis. Individual fish weight was taken on a portable digital weighing scale and the total length using a fish measuring board. The specimens were then tagged and photographed using a digital camera (Canon IXUS 275 HS, 12× optical zoom). Specimen photography was standardized using a wooden tripod stand with inserted mesh cradle for displaying fish. The mesh cradle prevents shape variations which would arise from differences in weight when lying on a plane surface (Muir et al. 2012). Digital images were always taken from the left side of each specimen displayed on a cradle at a focal length of $33 \mathrm{~cm}$. Fish sampling/field was conducted in the dry season, Months of July to December 2016, and a total of 490 fish specimens were analyzed.

Fish coefficient of condition/condition factor

In general, the coefficient of condition or condition factor of an organism can be regarded as a measure of suitability in an environment. Condition factor is also regarded as a degree of the general physical health of fish based on fatness (Ogle 2013). Furthermore, a thin fish with purportedly low condition value might suggest muscle wasting resulting from starvation or less favorable environmental conditions (Froese 2006). Therefore, the condition factor can be an important indicator for fisheries management to estimate favorable environmental conditions for a fishery. In the current study, to have an insight in the over-all well-being of fish populations from different habitats which could be an indicator of adaptability and or performance, we determined condition factor $(\mathrm{K})$ from the expression; $K=\frac{100 . \mathrm{W}}{L^{3}}$, where, $\mathrm{W}=$ weight of individual fish $(\mathrm{g})$ and $\mathrm{L}=$ Total length of individual fish (cm) (Ricker 1975).

Landmark acquisition

Landmark programming was conducted by two Thinplate-spline (Tps); Tps utility version 1.69 (TpsUtil) and Tps digitize version 1.40 (TpsDig) programs (Rohlf 2004; Zelditch et al. 2012). TpsUtil was used to build tps files from individual fish digital images. The tps files were then imported into TpsDig which was later used to digitize 10 Lms (Fig. 2) on each image and to generate a two dimensional x,y coordinates (Zelditch et al. 2012;
Park et al. 2013). Digital images were scaled along a ruler and all the 10 homologous Lms were digitized sequentially on the biological images (Fig. 2). The anatomical descriptions and location of each landmark are presented in Table 2 and Fig. 2. To minimize errors during Lms digitization, only one person performed the procedures. The Tps programs were freely downloaded from the site; http://life.bio.sunysb. edu/ee/rohlf/software.html (Zelditch et al. 2012).

\section{Data analysis}

Populations were pooled in different hierarchical levels (Ondhoro et al. 2016). One-way ANOVA was used to determine $\mathrm{K}$ variations among Nile tilapia populations using SAS for windows version 9.4. $\mathrm{K}$ values were taken as dependent variables and populations or population groups as explanatory variables. Morphological variation was analyzed using MorphoJ, vers. $1.06 \mathrm{~d}$ (Klingenberg 2011). MorphoJ is an Integrated Morphometrics Package (IMP) for conducting multivariate analysis for shape variations, (http://www.flywings.org. uk/morphoj_page.htm; (Zelditch et al. 2012). Landmark coordinates generated by TpsDig were imported into MorphoJ and shape information was extracted by Procrustes Superimposition. The existence of outliers in the shape data was inspected by graphically plotting cumulative frequency against squared Mahalanobis distance implemented by MorphoJ (Klingenberg 2011). The superimposed landmark coordinates were then used to generate a covariance matrix as input for multivariate analyses; Principle Component Analysis (PCA), Canonical Variate Analysis (CVA), and nonmetric multidimensional scaling (NMDS). PCA was performed to investigate the main features of shape variation in samples and morpho-space with the axis describing highest amount of variation used as the first principle component (PC1), the next highest amount of variability becomes PC2 and so on, until variability becomes insignificant and therefore less important to describe the data (Jolliffe 2002). CVA was performed as an ordination type which maximizes the separation or discrimination of specified populations (Klingenberg 2011). CVA uses the assumption that the covariance structure within the groups is the same, thus utilizes the pooled within-group covariance matrix to separate populations (Klingenberg 2011; Zelditch et al. 2012). In case CVA violated the assumption, we conducted NMDS to validate results. With NMDS, a smaller number of axes are a priori chosen 

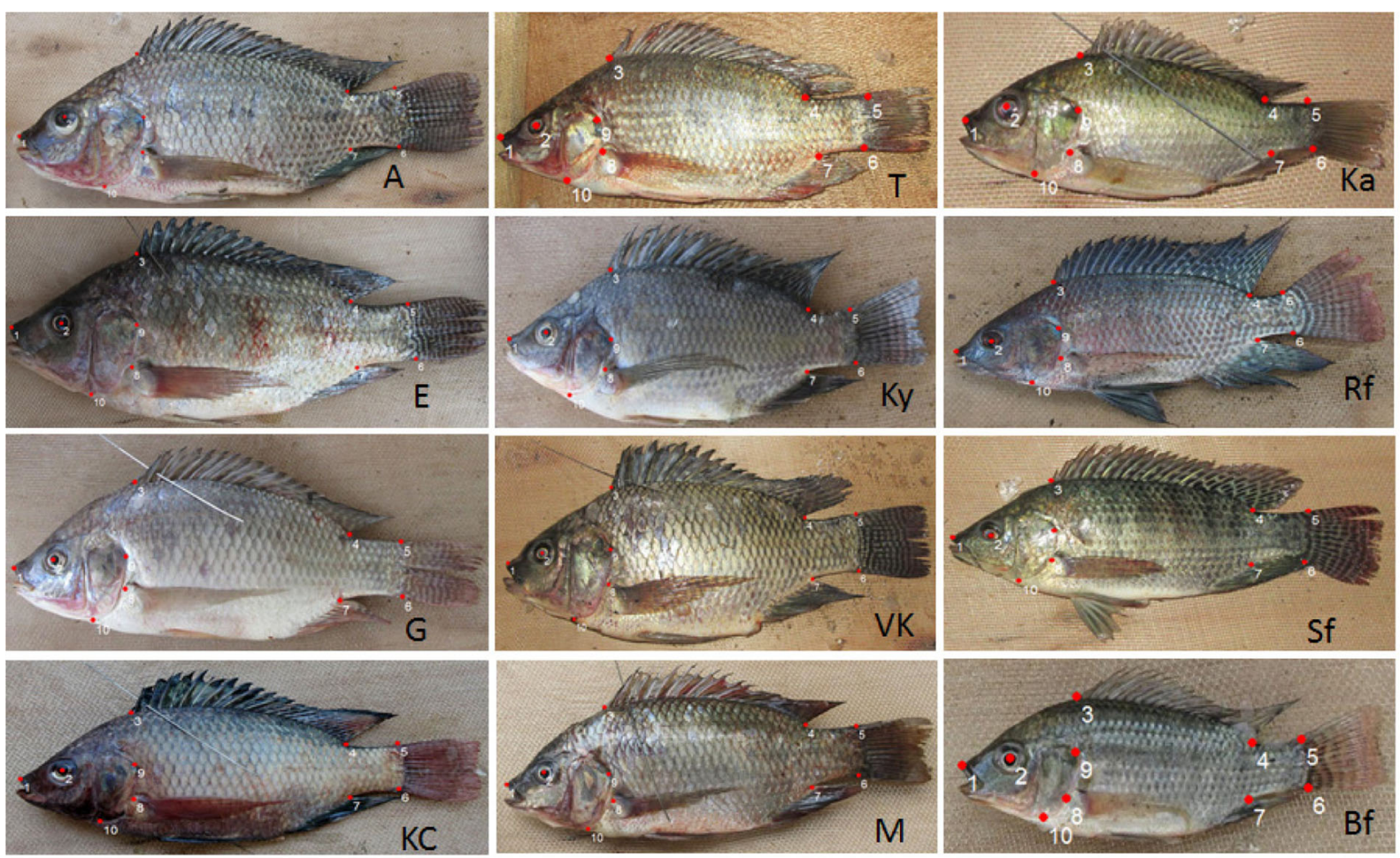

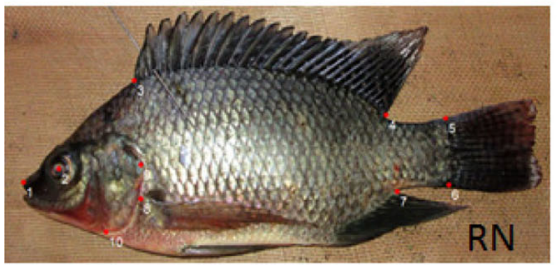

Fig. 2 Representatives of Nile tilapia populations from EA illustrating digitized landmarks used in geometric morphometrics. $\mathrm{A}=$ Albert, $\mathrm{E}=$ Edward, $\mathrm{G}=$ George, $\mathrm{KC}=$ Kazinga Channel, $\mathrm{RN}=$

Table 2 Description of the landmark points, adopted and modified from, (Costa et al. 2010; Lorenz et al. 2014; Ndiwa et al. 2016; Peligro and Jumawan 2016)

\section{Landmark number Location description}

\begin{tabular}{ll}
\hline 1 & Upper tip of the snout/mouth \\
2 & Orbit/eye center \\
3 & Anterior insertion or origin of the dorsal fin \\
4 & Posterior insertion or origin of the dorsal fin \\
5 & Dorsal insertion of caudal fin \\
6 & Ventral origin of caudal fin \\
7 & $\begin{array}{l}\text { Posterior insertion of anal fin } \\
8\end{array}$ \\
9 & $\begin{array}{l}\text { Dorsal base of pectoral fin or anterior origin } \\
\text { of pectoral fin }\end{array}$ \\
10 & $\begin{array}{c}\text { Most posterior edge of operculum or apex } \\
\text { of the opercular spine }\end{array}$ \\
\hline
\end{tabular}

River Nile, T = Turkana, Ky=Kyoga, VK=Victoria Kakyanga, $\mathrm{M}=$ Mulehe, $\mathrm{Ka}=$ Kayumbu, $\mathrm{Rf}=$ Rwitabingi farm, $\mathrm{Sf}=$ Sindi farm and $\mathrm{Bf}=$ Bagena farm

and all the data are fitted to those dimensions, implying unlimited graphical space, contrary to PCA or CVA. Furthermore, NMDS is less sensitive and makes fewer assumptions about the data and therefore suits a wide variety of data sets (Holland 2008). NMDS was performed using paleontological statistical software 'PAST' (Hammer et al. 2001); http://palaeoelectronica.org/2001_1/past/issue1_01.htm).

\section{Results}

\section{Coefficient condition (K)}

Generally, all populations' K values were between 1.5 and three (Fig. 3). Fish farms had on average lower K values than the wild populations. Over-all, among the 
farms, Rwitabingi, indicated the least $\mathrm{K}$ values and significantly different from Sindi farm $(p<0.05)$ (Fig. 3a). Kazinga Channel, Victoria, George and Kyoga populations had equally high $\mathrm{K}$ values $(p>0.05)$. Native populations in Albert and Turkana indicated similar lower K values and not significantly different $(p>0.05$, but significantly different $(p<0.05)$ from other natural populations (Fig. 3a). K values between nonnative highaltitude populations was not significantly different $(\mathrm{p}>$ 0.05 ), but surprisingly indicated higher values (greater than 2$)$ and significantly different $(p<0.05)$ from Turkana, a native population (Fig. 3a). The subpopulations of L. Victoria showed $\mathrm{K}$ values greater than two each (Fig. 3b). One subpopulation, Kakyanga from the deeper waters, indicated a $\mathrm{K}$ value significant lower from the rest $(\mathrm{p}<0.05$; Fig. 3b). The remaining subpopulations (Gaba, Kamuwunga, Masese and Sango Bay) had relatively high $\mathrm{K}$ values on the same significance level.

Geometric morphometrics-all populations

The major trends of shape variation in all populations were derived from the Procrustes analysis as illustrated by PCA and the principle components (PCs) of the covariance matrix from which the first four PCs explained $60.8 \%$ of the total variance. Most of the populations overlapped to some extent along the first two PCs, but differentiation among populations was

a

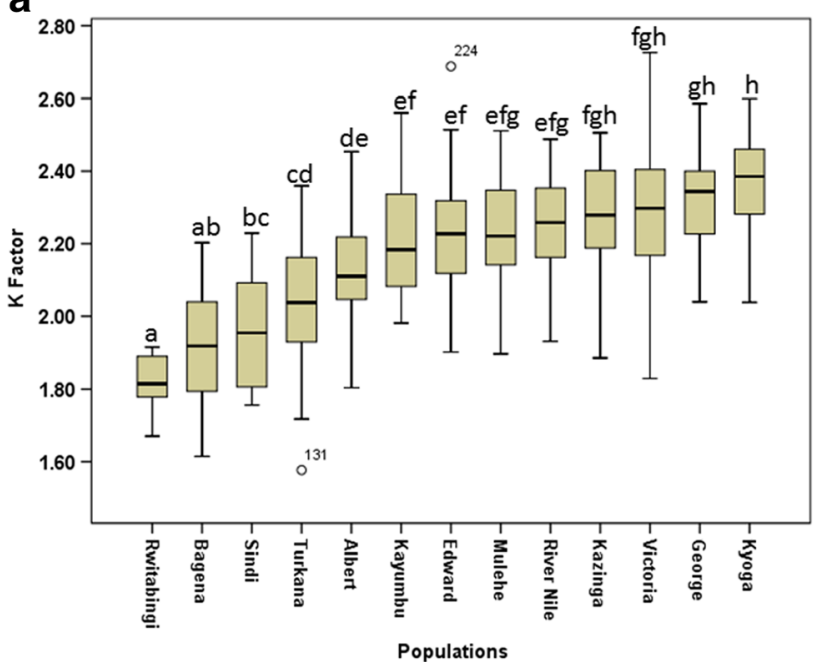

Fig. 3 Box plot graphs showing condition factor $(\mathrm{K})$ variations among Nile tilapia populations. Graph a represents comparisons for all populations; fish farms (Bagena, Rwitabingi and Sindi), observed on the on the graphs for PC1 and 2 (Figs. 4a, $\mathrm{b}$ and $\mathrm{c}$ ). The first PC axis indicated that River Nile, Lakes Victoria, Albert, George, Kyoga, Turkana and Sindi farm morphotypes were considerably more variable than the rest of the populations (Figs. $4 \mathrm{a}$ and c). Interestingly, PC2 showed Rwitabingi farm and again River Nile, Albert, Sindi, Edward, Kyoga, Victoria with Kazinga Channel and Bagena more variable (Fig. 4b and c). PC2 indicated evidence of morphological shape differences within some populations (River Nile, Albert, Kyoga, Victoria and Sindi). Bagena and Kayumbu populations showed the least PC scores (Figs. 4a and c). In general, shape change was encountered mainly in the anterior region of the fish, with the orientation of mouth tip (landmark1), dorsal fin region (Landmarks 3\&4), origin/insertion of the caudal fin (landmarks $5 \& 6$ ) opercular spine, dorsal insertion of pectoral fin (landmarks 9,8 respectively) (Fig. 4 W1 and W2). Result of CVA was congruent to PCA. Mostly, populations which indicated corresponding PC scores, tended to cluster together (Fig. 5a and c). Across CV1, River Nile, Kyoga, Albert Victoria and Sindi populations showed relatively higher CV scores. Similarly, CV1 and CV2 separated the populations in total accounting for $61.64 \%$ of variation. CVA results showed three morphotypic clusters formed between populations; Victoria-AlbertKyoga-River Nile (cluster 1); Kazinga Channel-Edward (cluster 2) and Bagena-Kayumbu (cluster 3) (Fig. 5a and c).

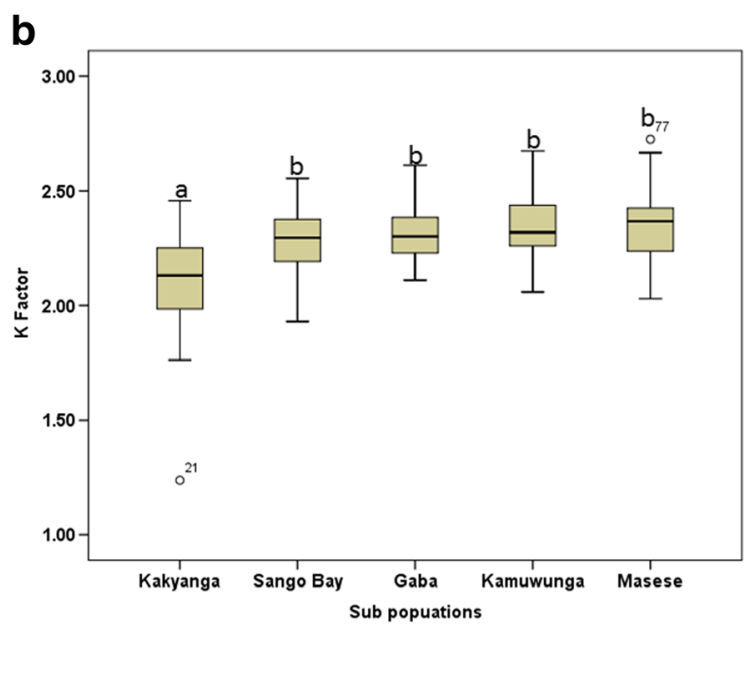

nonnative high altitude (Mulehe and Kayumbu), nonnative low altitude (Victoria and Kyoga) and the rest natives. Graph b represents singled out L. Victoria subpopulations 

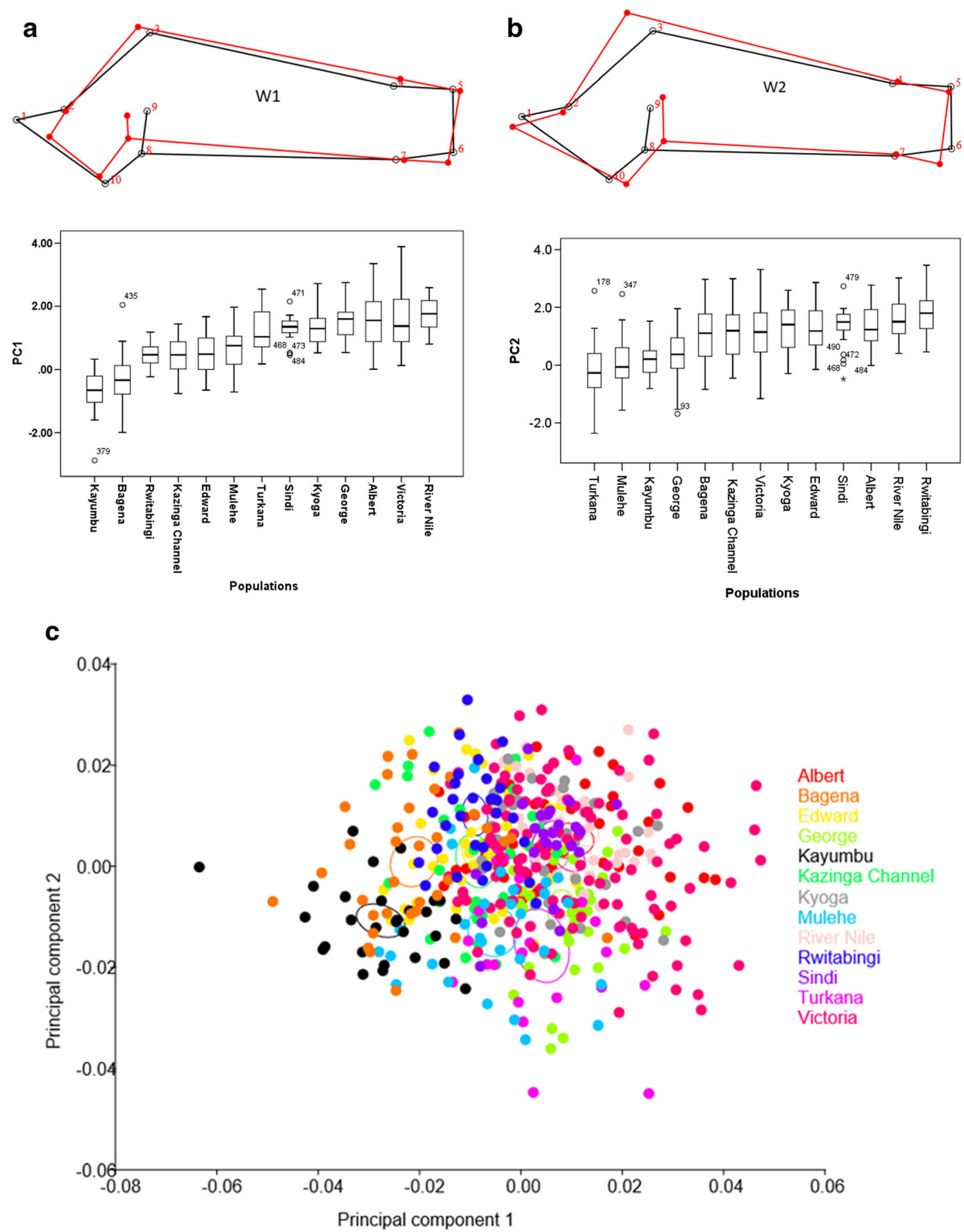

Fig. 4 Principle Component Analysis for all populations: $\mathbf{a}, \mathbf{b}$ and c represent $\mathrm{PC} 1, \mathrm{PC} 2$ scores and scatter plot for pooled components on a tangent space respectively. Circles in scatter plot represent $90 \%$ confidence ellipses drawn for means. W1 and W2 are wireframe graphs for PC1 and PC2 illustrating deformations for major features behind the observed shape variations, with blue and light blue wireframes indicating the shape change and ideal shape respectively. PCA graphs; $\mathbf{a}$ and $\mathbf{b}$ represent PC1 and PC2 scores respectively and $\mathrm{C}$ scatter plot for all pooled components on a tangent space. Circles in scatter graph represent $90 \%$ confidence ellipses drawn for means. W1 and W2 are wireframe graphs for PC1 and PC2 illustrating deformations for major features behind observed shape divergent. Blue wireframe graphs indicate the target shape (shape change) and light blue wireframe graphs indicate the starting shape (ideal shape). The PC scores, indicated on box plot graphs, were imported from MorphoJ, standardized for clear visualization and plotted using SAS statistical program 
NMDS results were consistent with CVA, with Victoria, Albert, Kyoga, and River Nile most similar, indicated by the shortest distance on minimal spanning tree (Fig. 5d). Hereby Kyoga was closer to Albert than to Victoria (Fig. 5d). Other pairs of similarity were Edward and Kazinga Channel, as well as Kayumbu and Bagena farm (Fig. 5d). The rest of the populations, generally demonstrated distal morphotypes (Fig. 5d).

a

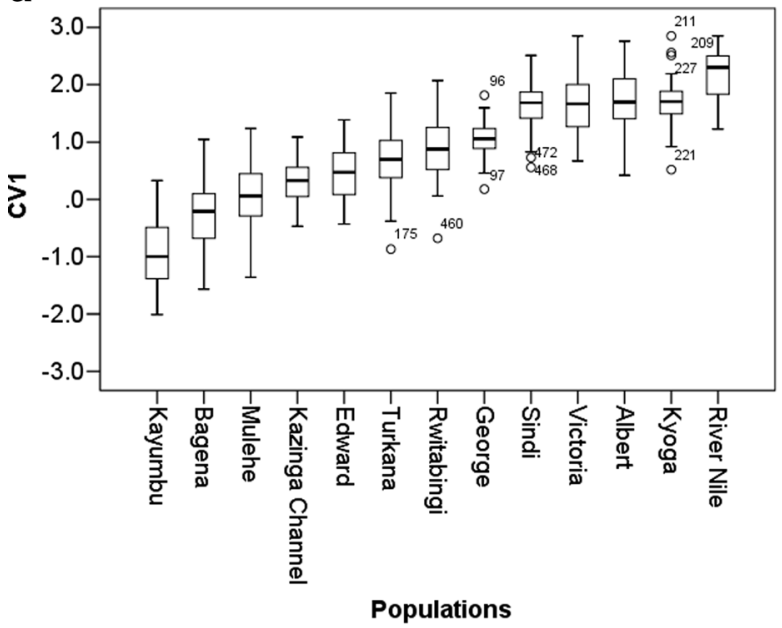

C

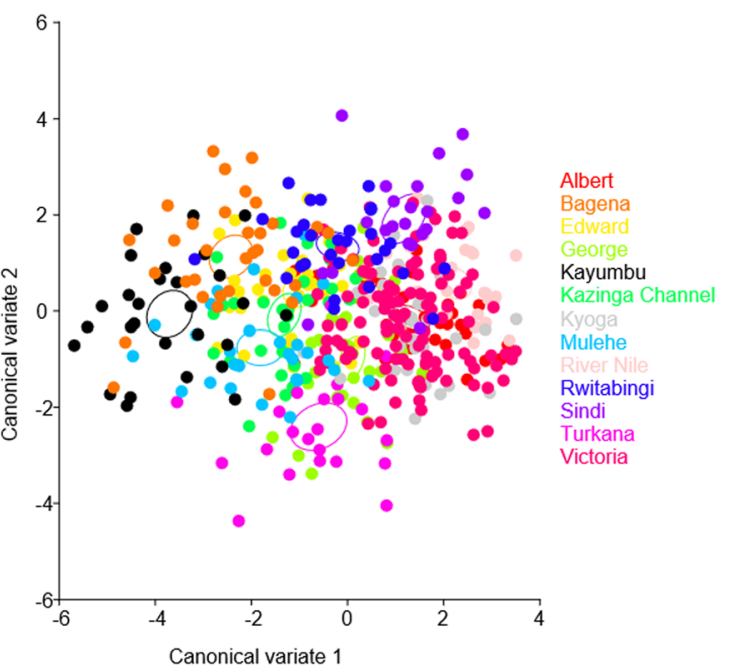

Fig. 5 Canonical Variate Analysis for all populations: a, b and c are CV1, CV2 scores and scatter plot for pooled variates on a tangent space. Circles in the scatter plot are confidence ellipses drawn for means at $90 \%$ probability, set at 10000 iterations. d represent NMDS plot for population morph closeness or distant explained by a minimal spanning tree set on Euclidean similarity index. CVA graphs; $\mathbf{a}$ and $\mathbf{b}$ are CV1 and CV2 respectively and $\mathbf{c}$ scatter plot for pooled variates on a tangent space. Circles in the
Geometric morphometrics-L. Victoria metapopulations

The shape variation among the five sub populations in L. Victoria was found to be more pronounced for Sango Bay and Kakyanga as indicated by the first PC (Fig. 6a and c). Generally, Masese, Kamuwunga and Gaba were observed to be less morphologically variable (Fig. 6a and c). On the other hand, PC2 loaded the rest of the
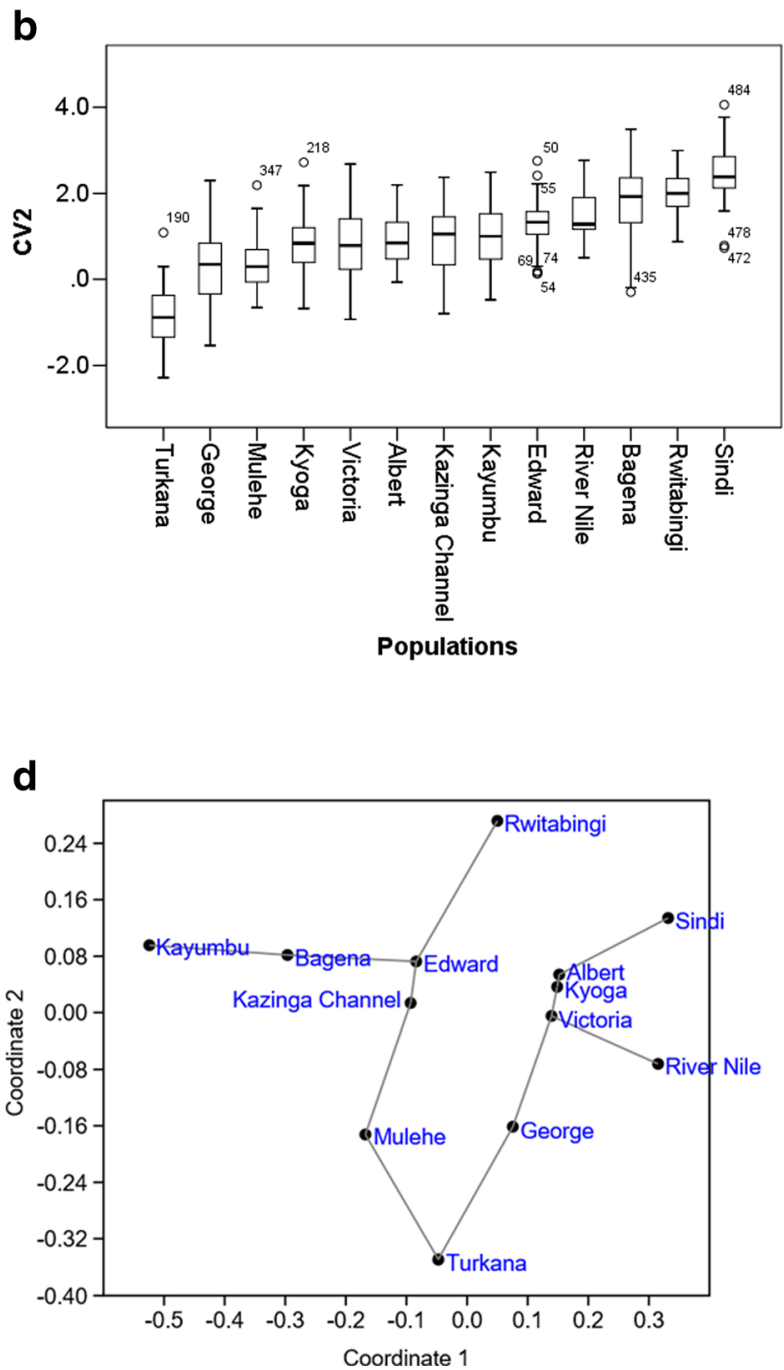

scatter graph are confidence ellipses drawn for means at $90 \%$ probability, set at 10000 iterations. d represent NMDS plot for population morph closeness or distant explained by a minimal spanning tree line set on Euclidean similarity index. The CV scores, indicated on box plot graphs, were imported from MorphoJ, standardized for clear visualization and plotted using SAS statistical program 
a
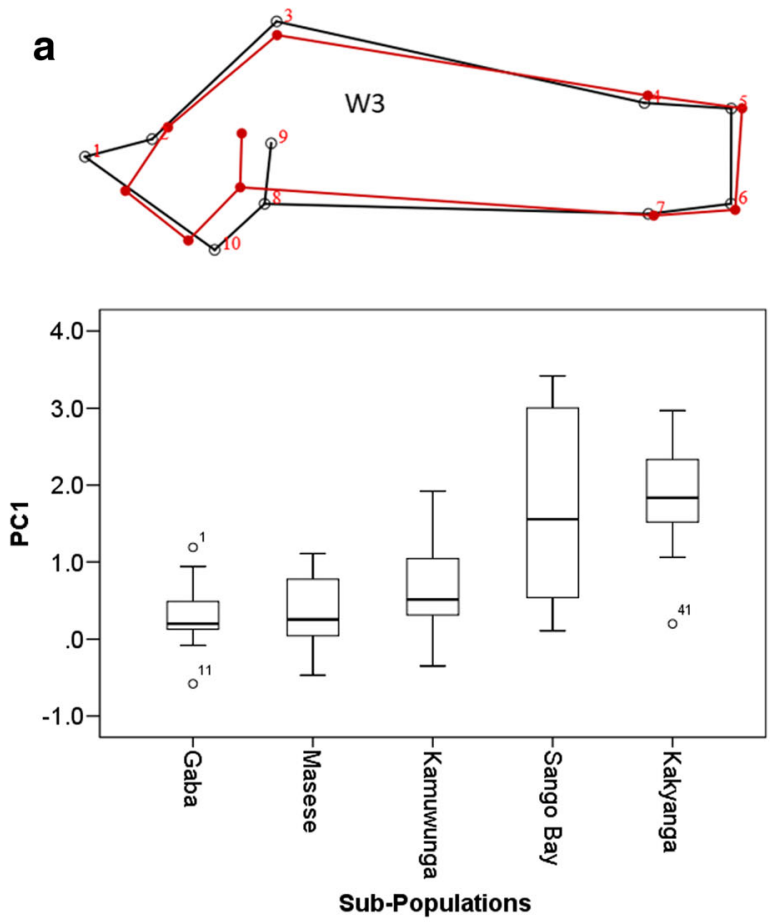

b
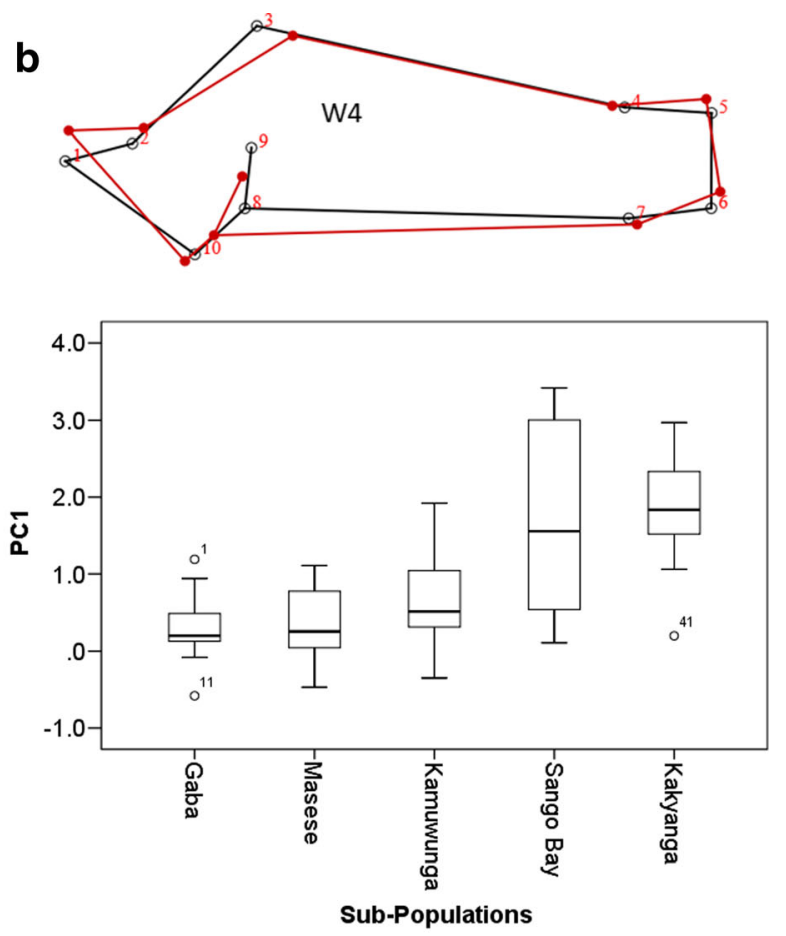

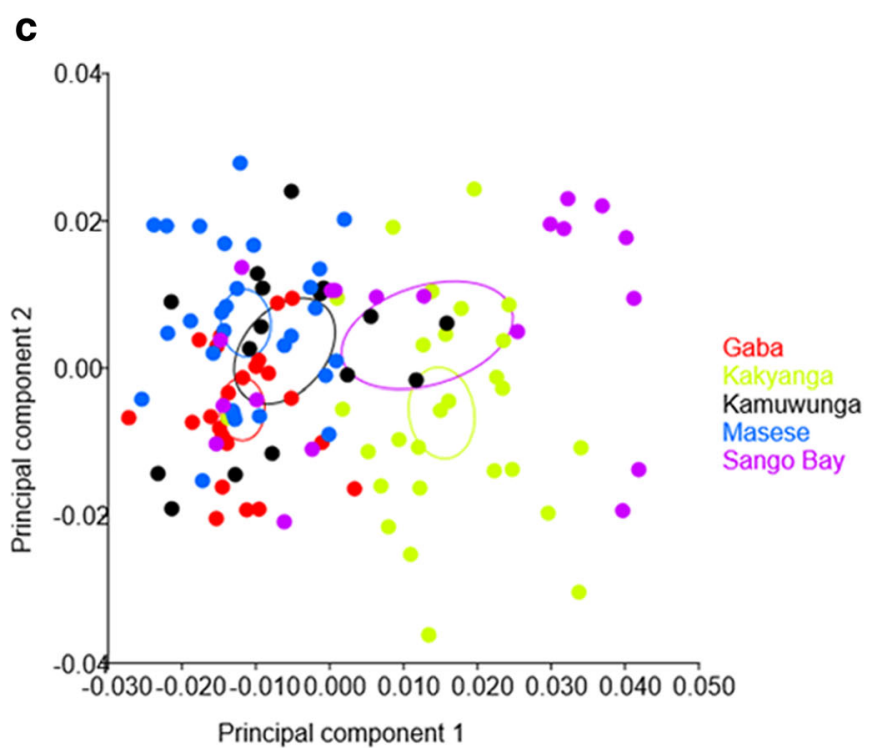

Fig. 6 Principle Component Analysis for L. Victoria: a, b and are PC1, PC2 scores and scatter plot for the pooled components respectively. Circles represent $90 \%$ confidence ellipses drawn for means. W3 and W4 are wireframes for PC1 and PC2 illustrating deformations for major features behind observed shape divergent, with blue and light blue indicating the shape change and ideal shape respectively. PCA graphs; $\mathbf{a}$ and $\mathbf{b}$ represent PC1 and PC2 scores respectively and $\mathbf{c}$ scatter plot for the pooled components.

populations with Masese, Sango Bay and Kamuwunga scoring higher on the axis (Fig. 6b). The major features

Circles represent $90 \%$ confidence ellipses drawn for means. W3 and W4 are wireframe graphs for PC1 and PC2 illustrating deformations for major features behind observed shape divergent. Blue wireframe graphs indicate the target shape (shape change) and light blue wireframe graphs indicate the starting shape (ideal shape). The PC scores for the graphs (a and b) were plotted similarly to Fig. 4

for shape divergence were the same landmarks for the anterior region like the other populations (Fig. $6 \mathrm{~W} 3$ 
a

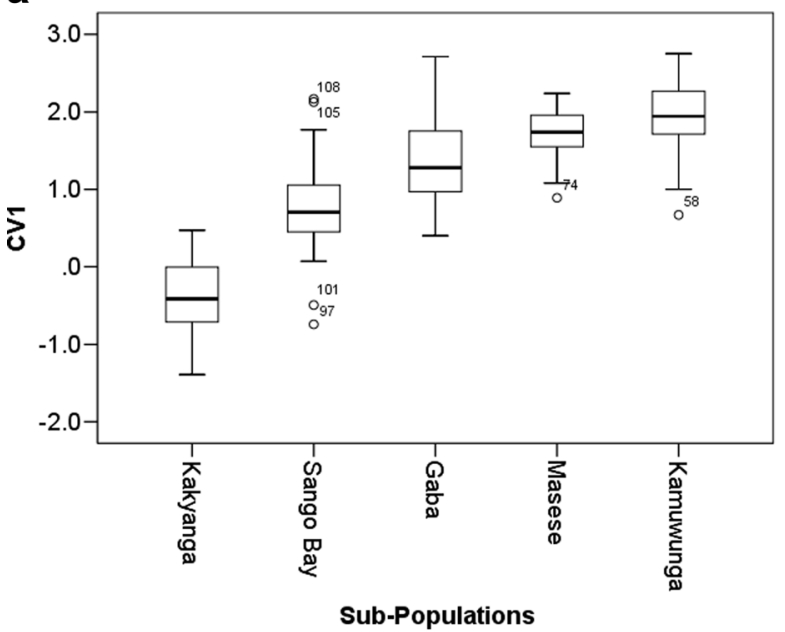

C

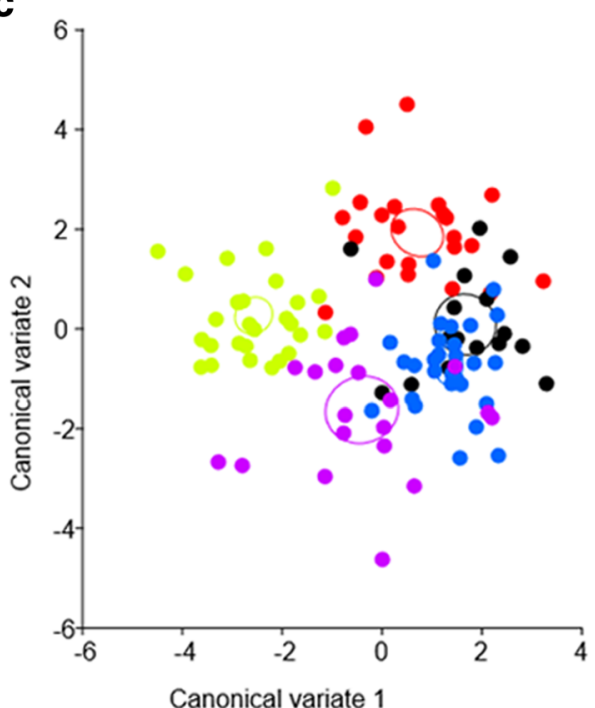

Fig. 7 Canonical Variate Analysis for L. Victoria: a, b and c represent $\mathrm{CV} 1, \mathrm{CV} 2$ scores and scatter plot for the pooled variates respectively. Circles in the scatter graph are confidence ellipses drawn for means at $90 \%$ probability, set at 10000 iterations. d represent NMDS plot for population morph closeness or distant explained by a minimal spanning tree set on Euclidean similarity index. CVA graphs; $\mathbf{a}$ and $\mathbf{b}$ represent CV1 and CV2 scores

and W4). The first three canonical variates extracted from the five sub populations explained $92 \%$ of the total variance, with $54.5 \%$ for CV1. Clear separation or discrimination of the sub populations was observed along CV1 axis where Kamuwunga-Masese were observed to form a cluster (Fig. 7c). Kakyanga, Sango Bay and Gaba sub populations were isolated on the CV axis. Similarly, analytical results from NMDS were consistent with CVA, and indicated b

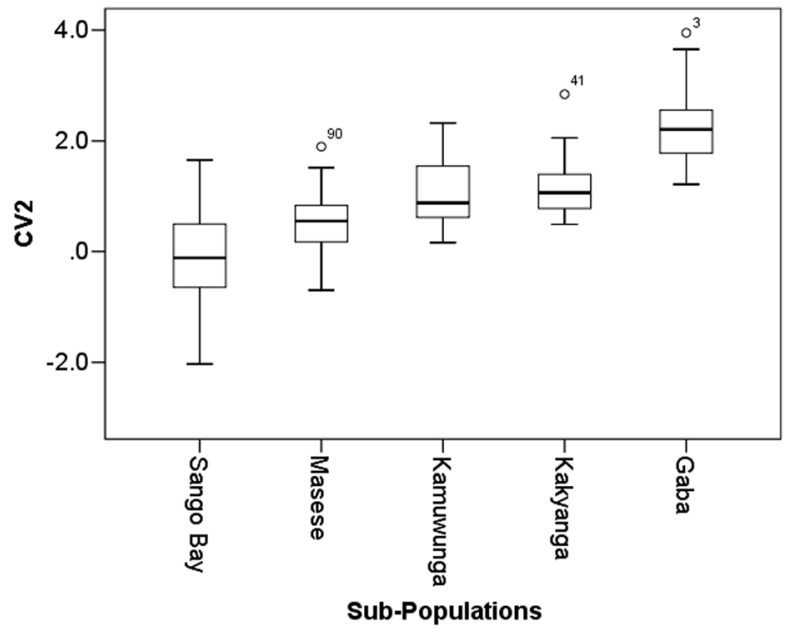

d

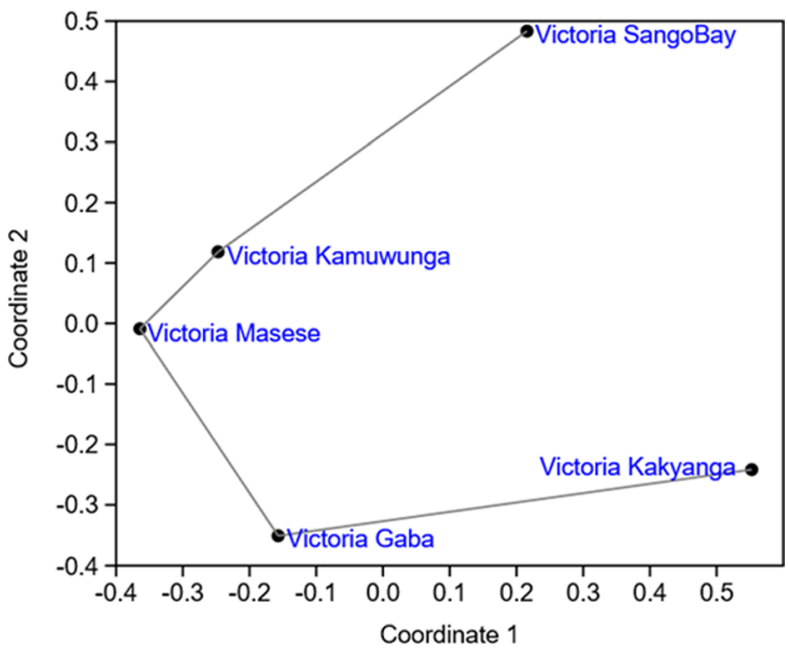

respectively and $\mathbf{c}$ scatter for the pooled variates. Circles in the scatter graph are confidence ellipses drawn for means at $90 \%$ probability and set at 10000 iterations. $\mathbf{d}$ represent NMDS plot for population morph closeness or distant explained by a minimal spanning tree line set on Euclidean similarity index. Graphs a and b were produced in the same way as in Fig. 5

close morphotypes between the subpopulation pair, Kamuwunga and Masese (Fig. 7d).

\section{Discussion}

Fisheries in developing countries are negatively impacted by poor enforcement and adherence to regulatory policies. One example of this failure in fisheries 
management are the Great Lakes of Eastern Africa, which are vital for the rapidly increasing human population in the region, but are also biodiversity hotspots with a remarkable number of endemic fish species (LoweMcConnell 2003). Over the past six decades the resources have been impacted majorly by anthropogenic activities (Mugidde 1993; Ogutu-Ohwayo et al. 1997; Verschuren et al. 2002). One of the most affected fish species in the region is Nile tilapia, which has had a significant impact following translocation to various habitats including aquaculture. The importance of the species in the region is significant and thoughtful attention is needed to ensure its future sustainability.

In the present study, $\mathrm{K}$ values for all the Nile tilapia populations were above 1.5 suggesting wellacclimatized populations in all habitats. All the $\mathrm{K}$ values observed in this study were in the range suggested as indicative for fish in suitable habitat. The $\mathrm{K}$ value depicts robustness or suitability of a species in a habitat and primarily reflects the fish's health status, sexual maturity and the degree of feeding (Williams 2000). It is expressed as weight per unit length and a values of above 1 implies a higher weight or fat fish in relation to length (Datta et al. 2013). Therefore, K seems relevant for the fisheries managers to predict the performance of the subsector in differing environments. Our $\mathrm{K}$ results correspond to earlier studies: Balirwa (1998) reported a K value of 2.12 for Nile tilapia from L. Victoria, 1.95 from L. Albert and 2.15 from L. Kyoga, and LoweMcConnell (1958), 2.1 from L. Turkana and 2.04 from L. George. However, the exact implications of such $\mathrm{K}$ values in this study are not entirely clear.

Condition factor $\mathrm{K}$ has been associated to other factors, including fish abundance and competition in ecosystems (Balirwa 1998; Bwanika et al. 2004; Otieno et al. 2013). For example, Balirwa (1998) reported that with declining fish populations in Lakes Kyoga and Victoria, less competition for food resources could have led to improvement of $\mathrm{K}$ values. The remarkable low $\mathrm{K}$ values observed under aquaculture might be linked to stress resulting from generally poor welfare of the fish under such conditions, like water quality, limited and low quality food, stock size and competition, among others. Stewart (1988) observed stress as a major factor underlying low reproduction in Nile tilapia nursery grounds around L. Turkana and dramatically negatively impacting on $\mathrm{K}$. The relatively low $\mathrm{K}$ values from the artificial systems was not a surprise, as it could be a symptom of poor management. It should nevertheless be noted that, albeit $\mathrm{K}$ is linked to nutritional factors/welfare, the proportionality in fish growth matters a lot when considering K. For instance, if a fish's weight increases proportionately with length, the fish becomes bigger but slender regardless of nutritional values from the environment. In this scenario, low $\mathrm{K}$ value might be recorded but could be misleading. The relatively low K values for L. Albert and Turkana populations together with Kakyanga subpopulation from L. Victoria observed with their realistic weights, could demonstrate this. More importantly, a fish might not actually grow to the desired table size despite improved $\mathrm{K}$, i.e. it remains small relative to its length. This was found in Nile tilapia from the high-altitude populations (see Table 1, for sizes), where all the fish were typically small but had better K values than Albert and Turkana where comparably bigger fish weights dominated (Table 1). Thus, this suggests that, $\mathrm{K}$ might be related to the actual physiology and genotypic of the fish (Le Cren 1951). Therefore, K could be more meaningful and reliable under experimental conditions, but sampling artefacts may influence it.

Quite often, it is assumed that eco-geographical variation in a species morphology is related to local adaptation. In the current study, the most striking morphological pattern regarding shape variability was found in seven populations; Victoria, Kyoga, Turkana, Albert, George and River Nile plus Sindi farm. The remaining six populations did not reflect this pattern. Interestingly, PCA results were generally consistent with $\mathrm{K}$ variables, except Sindi farm. Because K is considered as one of the test parameters for environmental conditions for organisms, most likely the observed Nile tilapia shape variations could have played a bigger role. This therefore suggests that the observed $\mathrm{K}$ variables might have been influenced by morphological diversification in the species, a remarkable feature for adaptation especially in new habitats. The noticeable shape diversification among populations was to some extent unexpected, apart from lakes Victoria and Kyoga. Environmental forces can fuel shape changes in organisms especially when colonizing new niches (Seebacher et al. 2016). This might be the reason for the morphological diversity especially in Lake Victoria and Kyoga where the introduction of Nile tilapia coincides with the disappearance of the indigenous Nile tilapia congeneric species. Following Nile tilapia introduction into these ecosystems, the native species (Oreochromis variabilis and 
Oreochromis esculentus), are reported to have vanished or disappeared with time. Several theories have been proposed for this, including competition for space or food and overfishing (Ogutu-Ohwayo 1990; Balirwa 1992; Lowe-McConnell 2010).

However, other reports have pinned possible intimate biotic interactions to have occurred. For example, Balirwa (1992) reported some form of hybridization in the Northern waters of L. Victoria, after observing phenotypic traits in some Tilapiine species identical to Nile tilapia. Relevant studies regarding cichlid gill morphological variation in L. Victoria have also been allied to hybridization (Witte et al. 2007). In addition, Tilapiine species (Oreochromis esculentus and Oreochromis niloticus) have also been reported to hybridize under experimental conditions (Welcomme 1966). Other GM studies regarding African cichlids (haplochromines) in lake Tanganyika reported pronounced shape variations in the F1 hybrids and concluded that hybridization among cichlids contribute significantly to morphological divergent (Stelkens et al. 2009; Kerschbaumer and Sturmbauer 2011). The outstanding morph divergent exhibited by Victoria and Kyoga populations might therefore be an expression of introgression between Nile tilapia and its native relatives which might be one possible explanation why the native Tilapiines vanished. Therefore, the morphology divergent observed could be the impacts of transgressive segregation effected during acclimatization, following introductions in the foreign homes, but this remains to be tested in the future studies.

Shape variation effects elaborated above, might as well be applicable to the River Nile morphotypes. The River Nile population was taken from the upper Murchison falls, between Victoria and Kyoga (Fig. 1). Nile tilapia from River Nile might be native below the herein mentioned barrier (Ogutu-Ohwayo 1990). However, it remains unknown if River Nile, upper falls, was stocked like in Lakes Victoria and Kyoga. However, due to drainage of water from Victoria to Kyoga via River Nile, there is undoubtedly a high probability for the species to have colonized this part of the river secondarily. The pronounced morphs observed in river might therefor result from similar forces like the introduced populations in other lakes. Also, the dynamic conditions in a river system might require an organism to develop anatomical features that can enhance its motion and endurance, particularly morphological traits like streamlined body shapes, with anterior body depths, that are developed for steady swimming (Langerhans and Reznick 2010). The well-developed streamlined morphotypes although could aid maneuverability in high water currents, may as well serve the best purpose for food and or prey search in such habitats. Streamlined body form of morphology is also critical for maximizing thrust and minimizing drag forces while swimming (Langerhans and Reznick 2010). This is consistent with our current findings as illustrated by the wireframe graphs. In our results, the fish streamline was clearly indicated by shape changes mainly at anterior body depth and tapering at the caudal peduncle. Also, shape changes were manifested at the operculum perhaps for maximizing respiration during locomotion in water turbulences. These morph features might have also developed in response to evading predators particularly Nile perch in lakes Albert, Victoria, Kyoga and Turkana. It must be noted that, Nile tilapia in EA is reportedly the only Tilapiine species to coexist with Nile perch, from both native and introduced locations (Balirwa 1998). The long history of Nile tilapia to live and share ecosystems with the predator is linked to ecological separation (Balirwa 1998; Mwanja 2000). While Nile perch prefers the open waters, it is believed that Nile tilapia shifted their niche to shore waters to avoid predation pressure (Ogutu-Ohwayo 1990). Therefore, it is feasible that structural complexity in the shore areas with their littoral aquatic vegetation might have further exacerbated the observed morphological diversification.

The observed similarity of shapes based on NMDS and CVA between the populations of Kyoga-VictoriaRiver Nile and Albert suggested a possible common genetic link which might result from a common source of the translocations. Nile tilapia was introduced into Lakes Victoria and Kyoga from their putative native source, Albert (Mwanja 2000). However, other sources reported that the species might have also been introduced into lakes Victoria and Kyoga from Lakes Edward, Turkana and from pond aquaculture at Kajjansi (Uganda) (Welcomme 1966; Trewavas 1983; Balirwa 1992; Pullin et al. 1997). The multiple stocking of the cichlid in the region is likely complex which makes its in-depth examining a pressing concern. The most remarkable closer morphotypes between Kyoga and Albert as illustrated by NMDS might explain historical stocking interval variations. However, it remains unclear how the stockings in the lakes especially Victoria and Kyoga were effected, whether it was the same or varying periods. These results reflect those of Mwanja (2000) 
who found Kyoga populations less genetically variable and associated it to more recent introductions in terms of history, contrary to Victoria metapopulation. Therefore, our NMDS and CVA results might be revealing the existing genetic intimacy between the introduced populations with their putative ancestral sources.

Similarity between populations of Kazinga Channel and Edward is likely to stem from their shared water channel. Fish from Kazinga Channel might be exchanged with L. Edward as the latter receives Kazinga Channel waters. Apart from L. George, the relatively minimal shape changes realized from the western rift valley populations; Edward and Kazinga Channel, suggests that these populations might be independent from anthropogenic influxes and or disturbances. The nonnative high-altitude populations, Kayumbu and Mulehe, showed similarly low morphological variability. Given that Nile tilapia is relatively a warm water species, one would undoubtedly expect the hostile environment, characterized by low water temperatures (Tibihika et al. 2016) to have significant role on the fish body form. This suggests that the populations might be of recent introduction and hence less variable morphotypes. However, the low variability in the marginal habitat might also result from lack of a native population that could induce variation via introgression (Tibihika et al. 2015), or by the higher selection pressure that initially might have reduced the introduced variation.

The noticeable shape changes in George population that differed from Kazinga Channel and Edward (closest neighbors), might be attributed to a bottleneck effect from overfishing and water contamination. Reduced fish numbers or demographic bottlenecked populations from overfishing with time are likely to be exposed to inbreeding and eventually lose genetic variation (Xenikoudakis et al. 2015). In addition to the eventualities of unfit generations, the inbred populations might further experience genetic drift which might influence the phonotypic traits and hence shape variations. Shao et al. (2007) reported significant morphological variation in inbred stocks of Chinese Minnow, Gobiocypris rarus. It should be noted that, although overfishing crosscuts in EA water bodies, significant fish overexploitation and accumulation of heavy metals (copper, zinc, cobalt and nickel) have been reported in L. George (Kamanyi 1996; Lowe-McConnell 2010) and (Swaibuh Lwanga et al. 2003) respectively. Heavy metals for example zinc and cadmium have been reported to have a pronounced effect on the morphology of fish like in the Indian major carps (Rani and Gupta 2015). Therefore, it is most likely that, the observed morphs from L. George might be under the multiple influence of both overfishing and water toxicity. However, of a more important note, the shape divergent encountered in George might also be a result of admixture. Mwanja (2000) reported that, in the 1970 s, while Nile tilapia fishery was booming on L. George, it prompted a fish processing plant on the lake. Later, overfishing (LoweMcConnell 2010) triggered importation of Nile tilapia from L. Albert to reinforce the dwindled stocks in L. George which culminated into Albert strain planted into L. George. Perhaps the interaction between Albert and George strains might further be behind the unexpected and encountered morphological divergence in the Lake, albeit subject to future studies.

Our results concur with those of Mwanja (2000) who found Nile tilapia populations from Kyoga closer to Albert and those of George distant from Edward. On the other hand, we differ as Victoria population was observed to be distant morphologically from Edward. This could be reasonably related to the differential methodological approaches in the two studies.

\section{Conclusions and recommendations}

Our results demonstrated that all the populations exhibited adequate ranges for condition factor, suggesting that they are "healthy" populations. Nevertheless, we found $\mathrm{K}$ not recommendable for reliance when depicting fisheries status. Morphological divergence was manifested mainly in River Nile, Lakes Victoria, Kyoga, Albert, George and Turkana plus one fish farm. The pronounced shape divergence observed between these populations were suspected to population admixture and other environmental cues. The noted morph closeness in some populations might be an indicator of possible genetic nearness which could be explained by the common ancestral home. The findings from this study are vital for management and conservation of the species. It is most likely that Nile tilapia populations from Kazinga Channel and L. Edward are devoid of anthropogenic activities and thus probably the only existing pure lines of the species. These populations may also be recommended for selective breeding in efforts aimed at elevating aquaculture productivity in the region. This study however, provides a benchmark in the dynamics of the species and hence, we recommend a more explicit 
consideration of follow-up of this work with molecular techniques while addressing genetic differentiation of these populations. Use of DNA bar-coding or Restriction site associated DNA (RAD) sequencing might allow detection of Nile tilapia diversification in the context of anthropogenic impacts. The future studies should broaden the scope of investigation for instance to include the populations below Murchison Falls, along River Nile and examine in-depth within population variations. Additionally, the same approach should also be true for all the great lakes, including other water bodies like Kivu, Bunyonyi and Baringo as the species variability might be at large.

Acknowledgements Open access funding provided by University of Natural Resources and Life Sciences Vienna (BOKU). The work was financed by the Austrian Partnership Programme in Higher Education and Research for Development - APPEAR, a programme of the Austrian Development Cooperation (ADC) and implemented by the Austrian Agency for International Cooperation in Education and Research (OeAD). Special thanks to Kachwekano Zonal Agricultural Research and Development Institute-National Agricultural Research Organization-Uganda and Makerere University-Kampala, Uganda for their great assistance during field activities. We are also grateful to diligent efforts provided by the Fisheries Officers from East African respective water bodies, more especially, a senior research officer, Mr. John Malala of L. Turkana (KEMFRI) for his memorable support.

\section{Compliance with ethical standards}

Conflict of interest The authors declare that they have no conflict of interest.

Ethical approval All applicable international, national, and/or institutional guidelines for the care and use of animals were observed and henceforth followed.

Open Access This article is distributed under the terms of the Creative Commons Attribution 4.0 International License (http:// creativecommons.org/licenses/by/4.0/), which permits unrestricted use, distribution, and reproduction in any medium, provided you give appropriate credit to the original author(s) and the source, provide a link to the Creative Commons license, and indicate if changes were made.

\section{References}

Agnèse JF, Adépo-Gourène B, Abban EK, Fermon Y (1997) Genetic differentiation among natural populations of the Nile tilapia Oreochromis niloticus (Teleostei, Cichlidae). Heredity 79(1):88-96. https://doi.org/10.1038/hdy.1997.126
Bakhoum SA, Sayed-Ahmed MA, Ragheb EA (2009) Genetic evidence for natural hybridization between Nile tilapia (Oreochromis niloticus; Linnaeus, 1758) and blue tilapia (Oreochromis aureus; Steindachner, 1864) in lake Edku, Egypt. Glob Vet 3(2):91-97

Balirwa JS (1992) The evolution of the fishery of Oreochromis niloticus (Pisces: Cichlidae) in Lake Victoria. Hydrobiologia 232(1):85-89. https://doi.org/10.1007/BF00014616

Balirwa JS (1994) The biology, ecology, population parameters and the fishery of the Nile tilapia, Oreochromis niloticus (L).26-38. https://doi.org/10.1007/BF00014616

Balirwa JS (1998) Lake Victoria wetlands and the ecology of the Nile tilapia, Oreochromis niloticus linn. Dissertation submitted in fulfilment of the requirements of the Board of Deans of Wageningen agricultural university and the academic Board of the International Institute for infrastructural, Hydraulic and Environmental Engineering for the Degree of DOCTOR. Balkema

Bookstein FL (1982) Foundations of morphometrics. Annu Rev Ecol Syst 13(1):451-470. https://doi.org/10.1146/annurev. es.13.110182.002315

Boyd CE (2004) Farm-Level issues in aquaculture certification: Tilapia. Auburn, Alabama 36831. Report commissioned by WWF-US in 2004. Auburn University, Auburn

Breno M, Leirs H, Van Dongen S (2011) Traditional and geometric morphometrics for studying skull morphology during growth in Mastomys natalensis (Rodentia: Muridae). J Mammal 92(6):1395-1406. https://doi.org/10.1644/10MAMM-A-331.1

Bwanika G, Makanga B, Kizito Y, Chapman L, Balirwa J (2004) Observations on the biology of Nile tilapia, Oreochromis niloticus L., in two Ugandan crater lakes. Afr J Ecol 42(s1): 93-101. https://doi.org/10.1111/j.1600-0633.2006.00185.x

Byrnes R (2010) Uganda: A country study. GPO for the Library of Congress, Washington

Cockerton H, Street-Perrott F, Leng M, Barker P, Horstwood M, Pashley V (2013) Stable-isotope (H, O, and Si) evidence for seasonal variations in hydrology and Si cycling from modern waters in the Nile Basin: implications for interpreting the quaternary record. Quat Sci Rev 66:4-21. https://doi. org/10.1016/j.quascirev.2012.12.005

Corse E, Neve G, Sinama M, Pech N, Costedoat C, Chappaz R, Gilles A (2012) Plasticity of ontogenetic trajectories in cyprinids: a source of evolutionary novelties. Biol J Linn Soc 106(2):342-355. https://doi.org/10.1111/j.10958312.2012.01873.x

Costa C, Vandeputte M, Antonucci F, Boglione C, Menesatti P, Cenadelli S, Parati K, Chavanne H, Chatain B (2010) Genetic and environmental influences on shape variation in the European sea bass (Dicentrarchus Labrax). Biol J Linn Soc 101(2):427-436. https://doi.org/10.1111/j.10958312.2010.01512.x

Datta SN, Kaur VI, Dhawan A, Jassal G (2013) Estimation of length-weight relationship and condition factor of spotted snakehead Channa Punctata (Bloch) under different feeding regimes. SpringerPlus 2(1):436. https://doi.org/10.1186/21931801-2-436

Deines AM, Bbole I, Katongo C, Feder JL, Lodge DM (2014) Hybridisation between native Oreochromis species and introduced Nile tilapia $O$. niloticus in the Kafue River, 
Zambia. Afr J Aquat Sci 39(1):23-34. https://doi. org/10.2989/16085914.2013.864965

Dodson JJ, Bourret A, Barrette MF, Turgeon J, Daigle G, Legault M, Lecomte F (2015) Intraspecific genetic admixture and the morphological diversification of an estuarine fish population complex. PLoS One 10(4):e0123172. https://doi.org/10.1371/journal.pone.0123172

Eklöv P, Svanbäck R (2005) Predation risk influences adaptive morphological variation in fish populations. Am Nat 167(3): 440-452. https://doi.org/10.1086/499544

Eknath AE, Bentsen HB, Ponzoni RW, Rye M, Nguyen NH, Thodesen J, Gjerde B (2007) Genetic improvement of farmed tilapias: composition and genetic parameters of a synthetic base population of Oreochromis niloticus for selective breeding. Aquaculture 273(1):1-14. https://doi.org/10.1016/j. aquaculture.2007.09.015

El-Zaeem SY, Ahmed MMM, Salama ME-S, El-Kader WNA (2012) Phylogenetic differentiation of wild and cultured Nile tilapia (Oreochromis niloticus) populations based on phenotype and genotype analysis. Afr J Agric Res 7(19): 2946-2954. https://doi.org/10.5897/AJAR11.2170

Froese R (2006) Cube law, condition factor and weight-length relationships: History, meta-analysis and recommendations. J Appl Ichthyol 22(4):241-253. https://doi.org/10.1111/j.14390426.2006.00805.x

George TT (1995) The most recent nomenclature of tilapia species in Canada and the Sudan. Bull Aquac Assoc Can, Sp Pub 10: 33-37

Green J (2009) Nilotic lakes of the western rift. The Nile:263-286. https://doi.org/10.1007/978-1-4020-9726-3_14

Hammer Ø, Harper D, Ryan P (2001) PAST: paleontological statistics software package for education and data analysis Palaeontol. Electron 4:1-9

Holland SM (2008) Non-metric multidimensional scaling (MDS). Ava il able at: ht t p:// w w w u g a . edu/strata/software/pdf/mdsTutorial.pdf

ISSION EAIC (1960) East African Fisheries Research Organization Annual Report 1954/1955. East Africa High Commission, Tanganyika

Januszkiewicz AJ, Robinson BW (2007) Divergent walleye (Sander Vitreus)-mediated inducible defenses in the centrarchid pumpkinseed sunfish (Lepomis gibbosus). Biol J Linn Soc 90(1):25-36. https://doi.org/10.1111/j.10958312.2007.00708.x

Jolliffe I (2002) Principal Component Analysis and Factor Analysis. In: Principal Component Analysis. Springer Series in Statistics. Springer, New York

Kamanyi J (1996) Management strategies for exploitation of Uganda Fisheries Resources. FIRI Mimeo. February, 1996. Fisheries Research Institute, Uganda

Kerschbaumer M, Sturmbauer C (2011) The utility of geometric morphometrics to elucidate pathways of cichlid fish evolution. Int J Evol Biol 2011:1-8. https://doi.org/10.4061/2011/290245

Klingenberg CP (2011) MorphoJ: an integrated software package for geometric morphometrics. Mol Ecol Resour 11(2):353357. https://doi.org/10.1111/j.1755-0998.2010.02924.x

Kolding J (1992) Population dynamics and life-history styles of Nile tilapia, Oreochromis niloticus, in Ferguson's Gulf, Lake Turkana, Kenya. Environ Biol Fish 37:25-46. https://doi. org/10.1007/BF00000710
Langerhans RB, Reznick DN (2010) Ecology and evolution of swimming performance in fishes: predicting evolution with biomechanics. Fish locomotion: an eco-ethological Perspective:200-248

Le Cren E (1951) The length-weight relationship and seasonal cycle in gonad weight and condition in the perch (Perca Fluviatilis). $\mathrm{J}$ Anim Ecol:201-219, https://doi.org/10.2307/1540

Lorenz O, Smith P, Coghill L (2014) Condition and morphometric changes in tilapia (Oreochromis sp.) after an eradication attempt in southern Louisiana. NeoBiota 20:49. https://doi. org/10.3897/neobiota.20.506

Lowe-McConnell RH (1958) Observations on the biology of Tilapia Nilotica Linné in east African waters. Rev Zool Bot Afr 57:129-170

Lowe-McConnell R (2003) Recent research in the African Great Lakes: fisheries, biodiversity and cichlid evolution. In: Freshwater Forum, pp 4-64

Lowe-McConnell R (2010) Fisheries and cichlid evolution in the African Great Lakes: progress and problems. https://doi. org/10.1608/FRJ-2.2.2

Maderbacher M, Bauer C, Herler J, Postl L, Makasa L, Sturmbauer C (2008) Assessment of traditional versus geometric morphometrics for discriminating populations of the Tropheus Moorii species complex (Teleostei: Cichlidae), a Lake Tanganyika model for allopatric speciation. J Zool Syst Evol Res 46(2):153-161. https://doi.org/10.1111/j.14390469.2007.00447.x

Mallet J (2007) Hybrid speciation. Nature 446(7133):279-283. https://doi.org/10.1038/nature0570

Mekkawy IA, Mohammad AS (2011) Morphometrics and Meristics of the three Epinepheline species: Cephalopholis Argus (Bloch and Schneider, 1801), Cephalopholis Miniata (Forsskal, 1775) and Variola Louti (Forsskal, 1775) from the Red Sea, Egypt. J Biol Sci 1(11):10-21. https://doi. org/10.3923/jbs.2011.10.21

Moczek AP, Sultan S, Foster S, Ledón-Rettig C, Dworkin I, Nijhout HF, Abouheif E, Pfennig DW (2011) The role of developmental plasticity in evolutionary innovation. Proc R Soc Lond B Biol Sci 278(1719):2705-2713

Mugidde R (1993) The increase in phytoplankton primary productivity and biomass in Lake Victoria (Uganda). Verh Int Ver Limnol 25:846-849

Muir A, Vecsei P, Krueger C (2012) A perspective on perspectives: methods to reduce variation in shape analysis of digital images. Trans Am Fish Soc 141(4):1161-1170. https://doi. org/10.1080/00028487.2012.685823

Mwanja W (2000) Genetic biodiversity and evolution of two principal fisheries species groups, the labeine and tilapiine, of Lake Victoria, East Africa. Ph. D. thesis, Ohio State University, Cleveland, Ohio

Ndiwa TC, Nyingi DW, Claude J, Agnèse J-F (2016) Morphological variations of wild populations of Nile tilapia (Oreochromis niloticus). Environ Biol Fish 99(5):473-485. https://doi.org/10.1007/s10641-016-0492-y

Njiru M, Nyamweya C, Gichuki J, Mugidde R, Mkumbo O, Witte $F$ (2012) Increase in anoxia in Lake Victoria and its effects on the fishery. In: Anoxia. InTech

Ogle DH (2013) FishR Vignette-Fish Condition and Relative Weights: AIFFD Chapter 10.1-12

Ogutu-Ohwayo R (1990) The decline of the native fishes of lakes Victoria and Kyoga (East Africa) and the impact of 
introduced species, especially the Nile perch, Lates niloticus, and the Nile tilapia, Oreochromis niloticus. Environ Biol Fish 27(2):81-96. https://doi.org/10.1007/BF00001938

Ogutu-Ohwayo R, Hecky RE, Cohen AS, Kaufman L (1997) Human impacts on the African great lakes. Environ Biol Fish 50(2):117-131. https://doi.org/10.1023/A:1007320932349

Ondhoro CC, Masembe C, Maes GE, Nkalubo NW, Walakira JK, Naluwairo J, Mwanja MT, Efitre J (2016) Condition factor, length-weight relationship, and the fishery of Barbus Altianalis (Boulenger 1900) in lakes Victoria and Edward basins of Uganda. Environ Biol Fish:1-12. https://doi. org/10.1007/s10641-016-0567-9

Otieno ON, Kitaka N, Njiru J (2013) Length-weight relationship, condition factor, length at first maturity and sex ratio of Nile tilapia, Oreochromis niloticus in Lake Naivasha, Kenya. Int J Fish Aquat Stud:67-72

Park PJ, Aguirre WE, Spikes DA, Miyazaki JM (2013) Landmarkbased geometric Morphometrics: what fish shapes can tell us about Fish evolution. Proceedings of the Association for Biology Laboratory Education 34:361-371

Peligro VC, Jumawan JC (2016) Assessment of fluctuating asymmetry in the body shapes of Nile tilapia (Oreochromis niloticus) from Masao river, Butuan city, Philippines. AACL Bioflux 9(3):604-613

Perrier C, Baglinière JL, Evanno G (2013) Understanding admixture patterns in supplemented populations: a case study combining molecular analyses and temporally explicit simulations in Atlantic salmon. Evol Appl 6(2):218-230. https://doi.org/10.1111/j.1752-4571.2012.00280.x

Petrtyl M, Kalous L, Memiș D (2014) Comparison of manual measurements and computer-assisted image analysis in fish morphometry. Turk J Vet Anim Sci 38(1):88-94. https://doi. org/10.3906/vet-1209-9

Ponton D, Carassou L, Raillard S, Borsa P (2013) Geometric morphometrics as a tool for identifying emperor fish (Lethrinidae) larvae and juveniles. J Fish Biol 83(1):14-27. https://doi.org/10.1111/jfb.12138

Popma T, Masser M (1999) Tilapia Life History and Biology. Southern Regional Aquaculture Centre. SRAC Publication No. 283, Stoneville

Pullin R, Palomares M-L, Casal C, Dey M, Pauly D (1997) Environmental impacts of tilapias. In: tilapia aquaculture , 554-570

Rani S, Gupta R (2015) Effect of heavy metals on the morphology and growth performance of Indian major carps. Ann Biol 31(1):117-121

Ricker W (1975) Computation and interpretation of biological statistics of fish populations. Bull Fish Res Board Can 191: 1-382

Robinson BW, Wilson DS (1994) Character release and displacement in fishes: a neglected literature. Am Nat 144(4):596627. https://doi.org/10.1086/285696

Rohlf FJ (2002) Geometric morphometrics and phylogeny. Morphol Shape Phylogeny:175-193, https://doi. org/10.1201/9780203165171.ch9

Rohlf F (2004) Tpsdig (version 1.40). Department of Ecology and Evolution, State University of New York at Stony Brook, New York. http://life.bio.sunysb.edu/ee/rohlf/software.html

Scharnweber K, Watanabe K, Syväranta J, Wanke T, Monaghan MT, Mehner T (2013) Effects of predation pressure and resource use on morphological divergence in omnivorous prey fish. BMC Evol Biol 13(1):132. https://doi. org/10.1186/1471-2148-13-132

Seebacher F, Webster MM, James RS, Tallis J, Ward AJ (2016) Morphological differences between habitats are associated with physiological and behavioural trade-offs in stickleback (Gasterosteus Aculeatus). Open Sci 3(6):160316. https://doi. org/10.1098/rsos.160316

Seehausen O (2004) Hybridization and adaptive radiation. Trends Ecol Evol 19(4):198-207. https://doi.org/10.1016/j. tree.2004.01.003

Shao Y, Wang J, Qiao Y, He Y, Cao W (2007) Morphological variability between wild populations and inbred stocks of a Chinese minnow, Gobiocypris rarus. Zool Sci 24(11):1094 1102. https://doi.org/10.2108/zsj.24.1094

Sinama M, Gilles A, Costedoat C, Corse E, Olivier J-M, Chappaz R, Pech N (2013) Non-homogeneous combination of two porous genomes induces complex body shape trajectories in cyprinid hybrids. Front Zool 10(1):22. https://doi. org/10.1186/1742-9994-10-22

Stelkens RB, Schmid C, Selz O, Seehausen O (2009) Phenotypic novelty in experimental hybrids is predicted by the genetic distance between species of cichlid fish. BMC Evol Biol 9(1):283. https://doi.org/10.1186/1471-2148-9-283

Stewart K (1988) Changes in condition and maturation of the Oreochromis niloticus L. population of Ferguson's gulf, Lake Turkana, Kenya. J Fish Biol 33(2):181-188. https://doi.org/10.1111/j.1095-8649.1988.tb05461.x

Swaibuh Lwanga M, Kansiime F, Denny P, Scullion J (2003) Heavy metals in Lake George, Uganda, with relation to metal concentrations in tissues of common fish species. Hydrobiologia 499(1):83-93. https://doi.org/10.1023/A:1026347703129

Tibihika PDM, Barekye A, Bykora E (2015) Fish species composition, abundance and diversity of Minor Lakes in south western Uganda/Kigezi region. Int J Sci Technol 4(5):204 213

Tibihika PDM, Okello W, Barekye A, Mbabazi D, Omony J, Kiggundu V (2016) Status of Kigezi minor lakes: a limnological survey in the lakes of Kisoro, Kabale and Rukungiri districts. Int J Water Resour and Environ Eng 8(5):60-73

Trewavas E (1983) Tilapiine fishes of the genera Sarotherodon, Oreochromis and Danakilia. British Museum (Natural History), London, https://doi.org/10.5962/bhl.title.123198

Verschuren D, Johnson TC, Kling HJ, Edgington DN, Leavitt PR, Brown ET, Talbot MR, Hecky RE (2002) History and timing of human impact on Lake Victoria, East Africa. Proc R Soc Lond B Biol Sci 269(1488):289-294. https://doi.org/10.1098/rspb.2001.1850

Vreven E, Teugels G, Adepo-Gourene B, Agnese J (1998) Morphometric and allozyme variation in natural populations and cultured strains of the Nile tilapia Oreochromis Niloticus (Teleostei, Cichlidae). Belg J Zool 128(1):23-34

Welcomme R (1966) Recent changes in the stocks of tilapia in Lake Victoria. Nature 212(5057):52-54. https://doi. org/10.1038/212052a0

Williams J (2000) The coefficient of condition of fish. Chapter 13 in Schneider, James C.(ed.) 2000. Manual of fisheries survey methods II: with periodic updates. Michigan Department of Natural Resources Fisheries Special Report 25

Wilson LA, MacLeod N, Humphrey LT (2008) Morphometric criteria for sexing juvenile human skeletons using the ilium. 
J Forensic Sci 53(2):269-278. https://doi.org/10.1111/j.15564029.2008.00656.x

Witte F, Wanink J, Kishe-Machumu M (2007) Species distinction and the biodiversity crisis in Lake Victoria. Trans Am Fish Soc 136(4):1146-1159. https://doi.org/10.1577/T05-179.1

Xenikoudakis G, Ersmark E, Tison JL, Waits L, Kindberg J, Swenson J, Dalén L (2015) Consequences of a demographic bottleneck on genetic structure and variation in the
Scandinavian brown bear. Mol Ecol 24(13):3441-3454. https://doi.org/10.1111/mec.13239

Zelditch ML, Swiderski DL, Sheets HD (2012) A Practical Companion to Geometric Morphometrics for Biologists: Running analyses in freely-available software. Free download from https://booksite.elsevier.com/9780123869036/ (18 June 2013) 